\title{
Elastic modulus of tree frog adhesive toe pads
}

\author{
W. Jon. P. Barnes • Pablo J. Perez Goodwyn • \\ Mohsen Nokhbatolfoghahai - Stanislav N. Gorb
}

Received: 4 November 2010/Revised: 26 May 2011/Accepted: 27 May 2011/Published online: 12 June 2011

(C) The Author(s) 2011. This article is published with open access at Springerlink.com

\begin{abstract}
Previous work using an atomic force microscope in nanoindenter mode indicated that the outer, 10- to $15-\mu \mathrm{m}$ thick, keratinised layer of tree frog toe pads has a modulus of elasticity equivalent to silicone rubber (5-15 MPa) (Scholz et al. 2009), but gave no information on the physical properties of deeper structures. In this study, micro-indentation is used to measure the stiffness of whole toe pads of the tree frog, Litoria caerulea. We show here that tree frog toe pads are amongst the softest of biological structures (effective elastic modulus 4-25 kPa),
\end{abstract}

Pablo Perez Goodwyn, our friend and collaborator, tragically died in a swimming accident during the summer of 2009. This paper is dedicated to his memory.

Electronic supplementary material The online version of this article (doi:10.1007/s00359-011-0658-1) contains supplementary material, which is available to authorized users.

P. J. P. Goodwyn · S. N. Gorb

Evolutionary Biomaterials Group,

Max Planck Institute for Metals Research,

Heisenbergstr. 3, 70569 Stuttgart, Germany

W. Jon. P. Barnes $(\bowtie)$

Centre for Cell Engineering, Institute of Molecular,

Cell and Systems Biology, Joseph Black Building,

University of Glasgow, Glasgow, Scotland G12 8QQ, UK

e-mail: Jon.Barnes@glasgow.ac.uk

M. Nokhbatolfoghahai

Biology Department, Faculty of Sciences,

University of Shiraz, Shiraz, Iran

e-mail: nokhbeh@hotmail.com

\section{S. N. Gorb}

Department of Zoology, Functional Morphology

and Biomechanics, Zoological Institute of the University of Kiel,

Am Botanischen Garten 1-9, 24098 Kiel, Germany

e-mail: sgorb@zoologie.uni-kiel.de and that they exhibit a gradient of stiffness, being stiffest on the outside. This stiffness gradient results from the presence of a dense network of capillaries lying beneath the pad epidermis, which probably has a shock absorbing function. Additionally, we compare the physical properties (elastic modulus, work of adhesion, pull-off force) of the toe pads of immature and adult frogs.

Keywords Tree frog - Adhesion · Micro-indentation . Effective elastic modulus $\cdot$ Litoria caerulea

\section{Introduction}

In non-flying animal species, the evolution of climbing, a prerequisite for the invasion of arboreal habitats, has necessitated the development of adaptations that reduce the risk of falling. In addition to claws found in many animal groups, there are also structural adaptations for increasing adhesion and friction that serve this role.

Although gluing and suction devices are found in some groups, such as echinoderms (Paine 1926; Feder 1955; Lavoie 1956; Thomas and Hermans 1985; Flammang et al. 1994, 1998; Flammang 1996; Berger and Naumov 1996; Flammang and Walker 1997; Santos and Flammang 2005; Santos et al. 2005a, b) and disk-winged bats (Schliemann 1970, 1971, 1974, 1975, 1983; Schliemann and Hoeber 1978; Schliemann and Rehn 1980; Thewissen and Etnier 1995; Riskin and Fenton 2001), the most common mechanisms for maintaining contact during climbing are dry and wet adhesion.

In dry adhesion, epitomised by the ability of geckos to climb smooth vertical surfaces and even run upside-down on ceilings, there is direct contact between toe pad and substrate, permitting adhesion by formation of intermolecular 
bonds (van der Waals forces) between the surfaces (Hiller 1968; Autumn et al. 2002; Huber et al. 2005a). This performance is achieved by the adhesive pads' hierarchical organisation, consisting of rows of lamellae bearing millions of tiny, branched setae (2- to $10-\mu \mathrm{m}$ wide, $100-\mu \mathrm{m}$ long), each of which ends in hundreds of flattened spatulae (Huber et al. 2005b). Because of their small size $(200 \mathrm{~nm} \times$ $200 \mathrm{~nm} \times 20 \mathrm{~nm}$ thick), spatulae can achieve intimate contact with the substrate (Persson and Gorb 2003; Varenberg et al. 2010).

In wet adhesion, on the other hand, a fluid layer lies between pad and substrate and adhesion is produced by the combined effect of capillarity (surface tension forces) and Stefan adhesion (viscosity forces). It is presumably this fluid that produces the long dissipative bonds necessary for good adhesion (Persson 2007). Capillary bridges elongate considerably before they break, and the energy stored in the stretched bridges is dissipated in the fluid rather than being used to break other interfacial bonds. The adhesive pads of both arboreal amphibians and a wide variety of insects utilise wet adhesion and the adhesive pads may be either 'hairy' like those of geckos (e.g. flies, beetles) or 'smooth' (e.g. stick insects, grasshoppers, ants, amphibians) (see reviews by Scherge and Gorb 2001; Barnes 2007).

Within the Amphibia, adhesive toe pads have evolved independently in at least seven different families of frog, giving rise to either torrent or tree frogs (Duellman and Trueb 1997), and in arboreal salamanders (Green and Alberch 1981). Within the frogs, there has been considerable convergent evolution, so much that it is usually not possible to identify the family from the appearance of the toe pads. Soft domed pads occur on the ventral surface of the tip of each digit, the specialised pad epithelium being delineated from normal skin by distinct grooves. The toe pad epithelium is stratified columnar, and the hexagonal, flat-topped epithelial cells are separated from each other at their tips by fluid-filled grooves (Ernst 1973; Green 1979; Emerson and Diehl 1980; Hanna and Barnes 1991; Smith et al. 2006). Mucous glands secrete watery mucus into these channels, so that adhering pads have a thin layer of fluid between pad and substrate (Federle et al. 2006), though, as described below, they may make contact in places to promote friction. Different methods, including scanning electron microscopy (Smith et al. 2006), transmission electron microscopy (Ernst 1973) and atomic force microscopy (Scholz et al. 2009), have revealed that the tops of the epithelial cells are not flat, but consist of a dense array of nanopillars, 300-400 $\mathrm{nm}$ in both diameter and height. Comparing these dimensions with the thickness of the fluid layer as determined by interference reflection microscopy $(<30 \mathrm{~nm})$ strongly suggests that the tips of the nanopillars will be in direct contact with the substrate, promoting the considerable shear forces that the pads can produce (Federle et al. 2006).

In many cases, surface roughness can increase friction, but it is usually detrimental to adhesion. Indeed, as has been pointed out by Persson et al. (2005), all natural surfaces are to some degree rough and this roughness occurs over several different length scales. Such materials do not stick to each other because the forces between neutral molecules are negligible at separations of only a few atomic distances and the roughness prevents sufficiently close contact between the surfaces (Kendall 2001). One solution to this problem is for the adhesive structure to be extremely soft, so that it conforms to the contours of the substrate, thus increasing actual contact (Peressadko et al. 2005). Thus, just as the performance of a tyre is as much about the properties of the rubber and its inflation pressure as about the structural features of the surface, so adhesion and friction in biological systems depend as much on the underlying properties of the materials they are made of as the physico-chemical state of the outermost layer.

The use of the atomic force microscope in nanoindenter mode indicates that the outer, keratinised layer of tree frog toe pads, here shown to be 10 - to $15-\mu \mathrm{m}$ thick, has a modulus of elasticity equivalent to silicone rubber (5-15 MPa) (Scholz et al. 2009), but gives no information on the physical properties of deeper structures. In this study, micro-indentation is used to measure the stiffness of the pad as a whole. By systematically varying the depth of indentation, we have been able to examine the degree to which the pad has a uniform stiffness. Additionally, we demonstrate differences between the properties of immature and mature frogs that may partially explain the increased adhesive efficiency of older compared to younger frogs (Wuttke et al. 2008). A preliminary account of these findings has been published in the abstract form (Barnes et al. 2005).

\section{Materials and methods}

\section{Animals}

White's tree frogs (Litoria caerulea White, Family Hylidae) were purchased from commercial suppliers and maintained in glass vivaria at $20-24^{\circ} \mathrm{C}$ using heat mats. The vivaria contained foliage, dishes of $\mathrm{Cu}$-free fresh water to maintain a high humidity, branches on which the frogs could climb and sphagnum moss for the frogs to burrow into, all on a gravel base. They were fed on live house crickets dusted with a calcium balancer and multi-vitamin supplement (Nutrobal, purchased from Peregrine Live Foods, Ongar, Essex, England) twice weekly. 
Light microscopy

Frogs were killed via a lethal dose of Benzocaine. Nine toes from each frog, four from the front and five from the back, were fixed in $0.1 \mathrm{M}$ phosphate-buffered $2.5 \%$ glutaraldehyde at $\mathrm{pH} 7.4$ for $24 \mathrm{~h}$. Specimens were then rinsed in phosphate-buffered sucrose, post-fixed in buffered $1 \%$ osmium tetroxide for $1 \mathrm{~h}$ and stained in $0.5 \%$ uranyl acetate. Specimens were dehydrated in an alcohol series and embedded in Araldite resin. Semi-thin sections $(1 \mu \mathrm{m})$ were cut on a Reichert Ultracut E ultramicrotome. These were then mounted on microscope slides, stained with $1 \%$ toluidine blue in $1 \%$ borax, and examined in a light microscope over a range of magnifications.

Periodic acid/Schiff staining was used to confirm the identity of structures in the toe pad region. The semi-thin sections were de-resinised in saturated sodium ethoxide for 15-20 min (Imai et al. 1968). They were then hydrated in an alcohol series and finally washed in running water for $10 \mathrm{~min}$. Sections were treated in $1 \%$ periodic acid for $10 \mathrm{~min}$, and then washed in running water for $10 \mathrm{~min}$. They were then transferred to Schiff's reagent for 20-30 min before being washed in running water for 15-30 min. Finally, they were stained in Weigert's haematoxylin for 5-10 min, dehydrated, cleared in xylene and mounted in the mounting medium, DPX (Electron Microscopy Sciences per Science Services Ltd, London, UK).

\section{White light interferometry}

White light interferometry (WLI) is a technique for touchless measurement of surface topography in three dimensions. In our experiments, carried out at room temperature $\left(24-26^{\circ} \mathrm{C}, 40-60 \% \mathrm{RH}\right)$, we used a Zygo NewView 5000 System (model 5010) to scan the toe pads of frogs used in the indentation studies described below. Metropro 7.9.0 software was used to calculate axial and transverse radii of curvature of the pads from their 3D surface profiles, information that is needed for the estimation of toe pad stiffness (see below). The frog was restricted, ventral side up, in a foam-lined clear plastic Petri dish, with the distal portion of the limb (forelimb or hind limb) passing through a hole in the lid. The limb was firmly fixed with duct tape so that it could not move, and only the toe pad to be examined was left exposed. Under these conditions, frogs usually remained passive for a period long enough (5-10 $\mathrm{min}$ ) to do the scan and, when freed, showed no signs of stress. These experiments, and the nanoindentation experiments that followed, were carried out on four frogs, two fully adult with snout-vent lengths (SVLs) of 71.5 and $74.5 \mathrm{~mm}$, and two immature
(28.05 and $28.55 \mathrm{~mm} \mathrm{SVL).} \mathrm{We} \mathrm{used} \mathrm{the} \mathrm{largest} \mathrm{toe} \mathrm{pads,}$ namely those on the third and fourth digits of the forelimbs.

\section{Indentation experiments}

Physical properties of the toe pads, including estimates of elastic modulus, work of adhesion and pull-off force, were studied by means of micro-indentation (Gorb et al. 2000; Kohane et al. 2003; Perez Goodwyn et al. 2006). Our experiments utilised a Basalt 01 microtribometer (Tetra $\mathrm{GmbH}$, Germany), with indentation being produced by spheres of three different sizes, a 1.5-mm-diameter sapphire sphere and glass spheres of 264- and 64- $\mu$ m diameter. The experiments were carried out at room temperature on frogs prepared as for white light interferometry. In all cases, the centre of the pad was indented.

The experimental procedure involved a cycle in which the pad was loaded and then, after a $5 \mathrm{~s}$ pause, unloaded again (Fig. 1). Applied load and depth of indentation were both measured (see Scherge and Gorb 2001 for details), and an indentation depth versus applied force curve generated for each indentation. From this curve, the effective elastic modulus can be estimated by fitting the curve according to the JKR theory (Johnson et al. 1971). This calculation requires information on the radius of curvature of both pad and indenter sphere and the spring constant of the load sensor. The spring constant was calculated experimentally by pressing on a solid surface (glass slide) and measuring the slope of the force/distance relationship $\left(\mathrm{N} \mathrm{m}^{-1}\right)$.

Using an unpublished program 'Fitting Tools' (written by A. Peressadko), the obtained force-indentation data, adjusted to account for any displacement of the load sensor (spring constant information), were fitted according to Johnson, Kendall and Roberts (JKR) contact theory (Johnson et al. 1971) (Eq. 1):

$a^{3}=\frac{R}{E_{\mathrm{eff}}}\left(P+3 W \pi R+\sqrt{\left\{6 W \pi R P+(3 W \pi R)^{2}\right\}}\right)$

where $a$ is the radius of the zone of contact between two smooth elastic spherical bodies, $E_{\text {eff }}$ is the effective elastic modulus, $R$ is the composite or effective radius of curvature of the two bodies in contact, $P$ is the force, and $W$ is the work of adhesion. Mathematically, $1 / R$ is the sum of the curvatures (inverse radii) of the two bodies (Eq. 2).

$\frac{1}{R}=\frac{1}{R_{1}}+\frac{1}{R_{2}}$

where, $R_{1}$ and $R_{2}$ are the radii of the toe pad and indenting sphere, respectively. Since we are measuring pad stiffness rather than elasticity per se, the effective elastic modulus was calculated from the fitting of the load curve. As the 

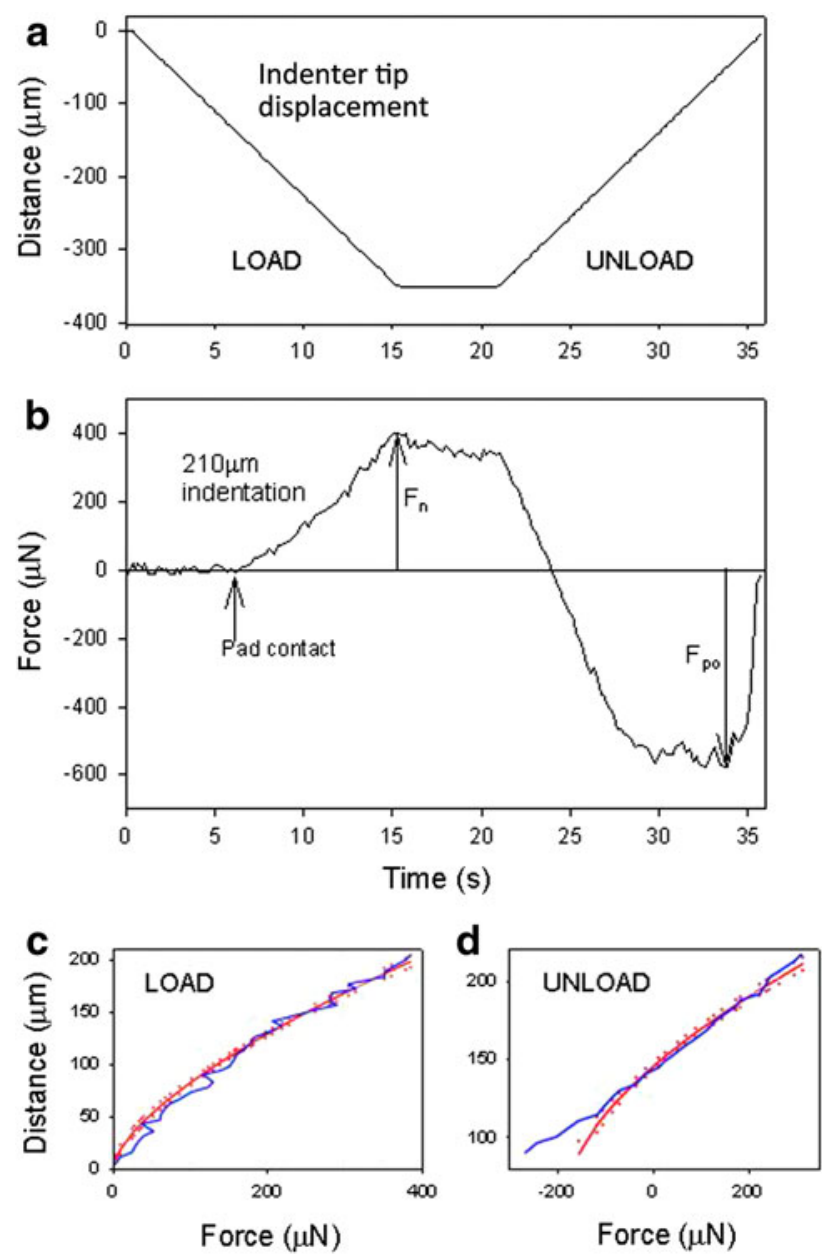

Fig. 1 Results from a representative indentation of one of the larger toe pads of a mature adult $L$. caerulea (area of pad, $10.2 \mathrm{~mm}^{2}$ ) using a sapphire sphere $(1.5 \mathrm{~mm}$ diameter) and an indentation velocity of $23 \mu \mathrm{m} \mathrm{s}^{-1}$. The movement of the indenter is plotted in (a), while the force resulting from indentation is shown in (b). $F_{\mathrm{n}}$ normal force; $F_{\mathrm{po}}$ pull-off force. c, $\mathbf{d}$ force distance plots (blue lines) and the fitted curves (red lines and dots representing 95\% confidence intervals). The effective elastic modulus estimated from (c) was $4.45 \mathrm{kPa}$, while the work of adhesion estimated from (d) was $0.08 \mathrm{Jm}^{-2}$

work of adhesion is 0 during loading, Eq. 1 simplifies to the Hertz equation (Hertz 1881)

$a^{3}=\frac{R \cdot P}{E_{\mathrm{eff}}}$

during the part of the cycle used for measuring the stiffness of the toe pad.

The radius of the zone of contact $(a)$ depends upon the reduced radius of contact of the two bodies $(R)$ and the indentation depth $(\delta)$ approximately according to the following equation (so long as $\delta \ll R$ ):

$\delta=\frac{a^{2}}{R}$

Combining Eq. 3 and 4 gives:
$\delta^{3}=\frac{1}{R}\left(\frac{P}{E_{\text {eff }}}\right)^{2}$

Since $R$ is a constant, $E_{\text {eff }}$ will be defined by the slope of the relationship between $\delta$ and $P$ (Scherge and Gorb 2001).

It should be noted that the Poisson's ratio of the sample is not known as we are dealing with a composite biological material. We thus estimate the effective elastic modulus $\left(E_{\text {eff }}\right)$ rather than the actual Young's modulus. They are linked by the following relationship:

$\frac{1}{E_{\text {eff }}}=\frac{3}{4}\left(\frac{1-v^{2}}{E}+\frac{1-v_{0}^{2}}{E_{0}}\right)$

where, $E$ is the Young's modulus and $v$ is the Poisson's ratio of the toe pad, the same parameters for the indenter being given by $E_{0}$ and $v_{0}$ (Johnson 1985). As the indenter material is much harder than the toe pad material, we can simplify Eq. 6 yielding:

$E_{\text {eff }}=\frac{4}{3}\left(\frac{E}{1-v^{2}}\right)$

The work of adhesion $(W)$ is the energy per unit of area $\left(\mathrm{Jm}^{-2}\right)$ needed to separate two bodies in contact. It was estimated from the unload curve using the curve-fitting procedure described above, but using the full JKR equation (Eq. 1) rather than the Hertz equation (Eq. 3). Although there are now two unknowns, $E_{\text {eff }}$ and $W$, they affect the relationship between $\delta$ and $P$ in different ways. $E_{\text {eff }}$ defines the slope of the relationship, while $W$ determines the position of the $P$ versus $\delta$ relationship on the $Y$-axis. Thus, both parameters may be estimated from the fitted curve.

The final piece of information obtainable from these measurements is the pull-off force $\left(F_{\mathrm{PO}}\right)$. This was measured directly from the force-displacement data.

A full account of the methodology of indentation appears in Scherge and Gorb (2001).

\section{Results}

Toe pad histology

Toe pads are located ventrally on the distal ends of each digit, and are delineated laterally and distally by a circumferal groove. Semi-thin sectioning (Fig. 2) shows that the toe pad epidermis consists of four layers of columnar epithelial cells. The outermost layer is keratinised and nonliving, and stains darkly in the sections. This layer is much thicker in the toe pad region than in dorsal or lateral skin (ca $15 \mu \mathrm{m}$ compared to ca $3 \mu \mathrm{m}$ ). In the region of the toe pad, but not elsewhere, the epithelial cells of this outer layer can also be seen to be separated from each other at their tips. The underlying dermis is highly vascularised in the ventral 


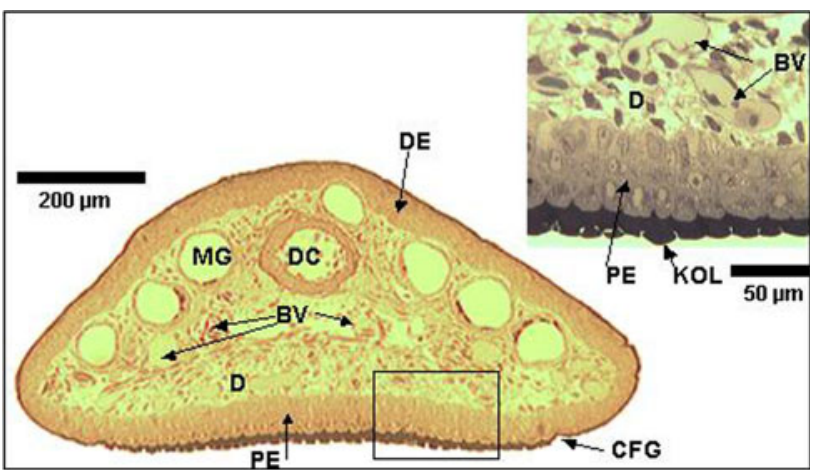

Fig. 2 Transverse section of toe of immature L. caerulea stained with toluidine blue to show its internal anatomy. Inset (top right) is an enlarged view of the region outlined by the rectangle to show the four layers of epithelial cells that constitute the epidermis of the toe pad. $B V$ blood vessels, $C F G$ circum-feral groove, $D$ dermis, $D C$ digital cartilage, $D E$ dorsal epidermis, $K O L$ keratinised outer layer, $M G$ mucous gland, $P E$ pad epidermis

part of the toe, blood vessels being identified by the presence of nucleated red blood cells within them. Mucous glands are located dorsally, just beneath the dorsal epidermis, and the presence of mucus was confirmed by Periodic acid/Schiff staining (not shown). In some sections, the mucous ducts can be seen below the glands. Such ducts will transport mucus to the surface of the toe pad, though ventrally located mucous glands (not visible in Fig. 2) also play the same role. Lying in the middle of the toe is the distal phalanx. Examination of serial sections demonstrates that the toe pad extends distally beyond the end of the phalanx.

\section{Surface topography}

When not in contact with a surface, the toe pads of L. caerulea are domed. Their radii of curvature were estimated by white light interferometry, which also provides an overview of their surface topography (Fig. 3a, b). Multiple measurements $(\leq 6)$ were made of each toe pad examined, and the mean values appear in Table 1 . The toe pads of the immature frogs were broader than they were long, which resulted in a greater radius of curvature in the transverse than the axial plane. No such difference was obvious in the mature adult frogs, where radii of curvature were considerably greater (i.e. their pads were flatter). The geometric mean of these transverse and axial plane values was used for the calculations of $E_{\text {eff }}$ and $W$ (see Table 1; Eq. 2).

Toe pad indentation

Micro-indentation studies were carried out on four frogs, two mature adults and two young immature frogs. In all cases, we indented the toe pad of the third digit of a forelimb. In our experiments, we systematically varied indentation
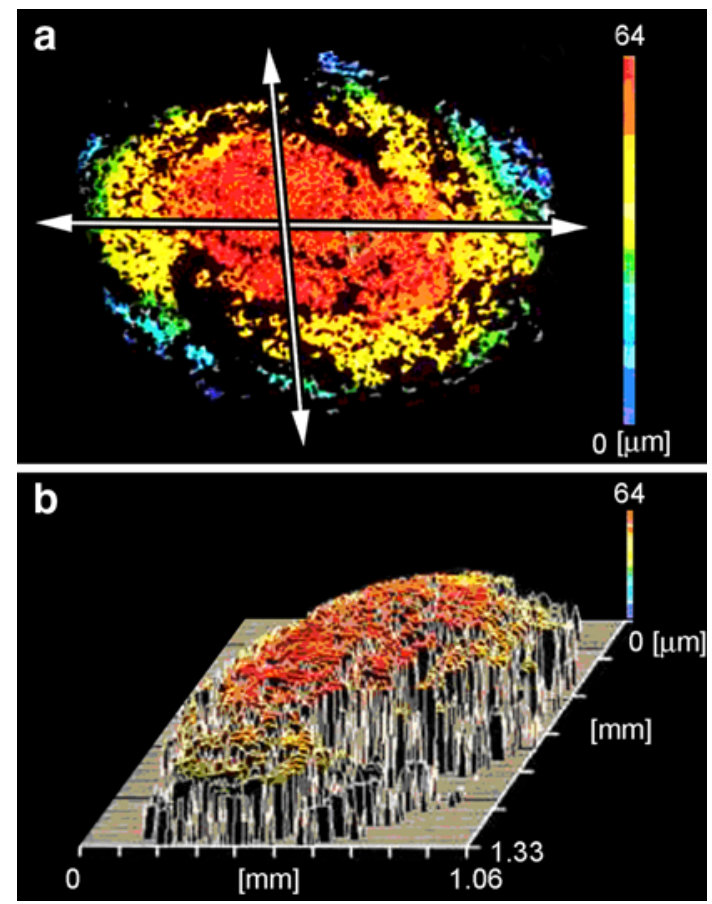

Fig. 3 Use of white light interferometry to measure toe pad curvature of one of the larger toe pads of a mature adult $L$. caerulea (area of pad, $10.2 \mathrm{~mm}^{2}$ ). a A pad height map; $\mathbf{b}$ a 3D reconstruction of toe pad shape (oblique plot). The radii of curvature estimated in this instance were: $X$ (transverse plane $)=5.1 \mathrm{~mm} ; Y($ axial plane $)=2.9 \mathrm{~mm}$

Table 1 Toe pad radii of curvature obtained by white light interferometry from digits 3 or 4 of the forelimbs

\begin{tabular}{llll}
\hline Frog & $X(\mathrm{~mm})$ & $Y(\mathrm{~mm})$ & $\sqrt{X . Y}(\mathrm{~mm})$ \\
\hline 1. SVL $=74.5 \mathrm{~mm}$ & 4.07 & 4.48 & 4.27 \\
2. SVL $=71.5 \mathrm{~mm}$ & 5.35 & 5.81 & 5.58 \\
3. SVL $=28.05 \mathrm{~mm}$ & 1.57 & 0.75 & 1.08 \\
4. SVL $=28.55 \mathrm{~mm}$ & 1.35 & 0.72 & 0.98 \\
\hline
\end{tabular}

SVL snout-vent length, $X$ transverse plane, $Y$ axial plane

depth and used three indenter tips of different diameter. Velocity of indentation was $15 \mu \mathrm{m} \mathrm{s}^{-1}$ for the immature frogs and for equivalent indentations of the adult frogs, and $23 \mu \mathrm{m} \mathrm{s}^{-1}$ for larger indentations of the adult frogs. We were able to measure pull-off force directly and estimate effective elastic modulus and work of adhesion as described in "Materials and methods". The measured spring constants of our force transducers were as follows: $104.5 \mathrm{~N} \mathrm{~m}^{-1}$ for the $1.5-\mathrm{mm}$ indenter, $206.6 \mathrm{~N} \mathrm{~m}^{-1}$ for the $264 \mu \mathrm{m}$ indenter and $104.3 \mathrm{~N} \mathrm{~m}^{-1}$ for the $64-\mu \mathrm{m}$ indenter (indenters were glued to springs acting as force transducers).

Examination of the raw data (Fig. 1) or a video of an indentation experiment (see Supplementary material) gives a good qualitative impression of the physical properties of the toe pad. The pad material is clearly very soft as it 

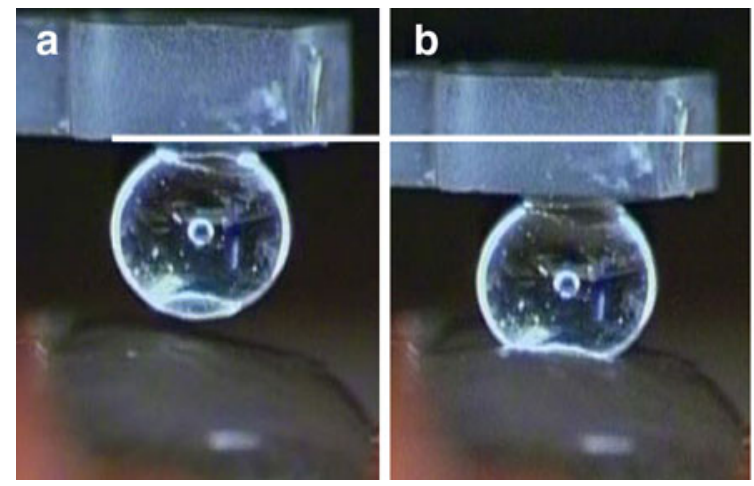

Fig. 4 Images of indentation with the $1.5 \mathrm{~mm}$-diameter sapphire sphere. a start of indentation, b maximum indentation, $\mathbf{c}$ point just before indenter loses contact with the pad during withdrawal of the

moulds to the shape of the indenter as the latter is pushed into the pad surface (Fig. $4 \mathrm{~b}$ ). The force $\left(F_{\mathrm{n}}\right)$ then declines slightly during the stationary period between load and unload (Fig. 1), indicating some viscoelasticity. During the unload part of the cycle, the surface is pulled outward before detaching (Fig. 4c) showing that it is sticky (tacky). Ultimately, it returns to its original shape, demonstrating that it is elastic rather than plastic.

Young's modulus of elasticity (or in our case the effective elastic modulus) is a quantitative measure of a material's stiffness; soft materials have a low value, while hard materials have a high one. Most of our data, irrespective of indentation depth or indenter diameter, lie in the range 4-25 kPa (Figs. 5a, 6a). We recognise that Hertz and JKR equations were not written for materials where there is both a stiffness gradient and evidence of viscoelasticity. Indeed, the relatively stiffer outer layer measured by atomic force microscopy (Scholz et al. 2009) means that shallow indentations are dominated by the bending of the outer layer giving a linear relationship of force and displacement. However, log:log plots of force/distance data from the deeper parts of deeper indentations do not deviate greatly from the slope of 0.67 predicted by Eq. 5 (data not shown), so we are confident that these stiffness values are approximately correct. The higher $E_{\text {eff }}$ values for shallower indentations (Fig. 4) can be presumed to reflect the influence of the stiffer outer layer. Our data also indicate that the tissue is slightly viscoelastic, but a different experimental design and other contact models are required to study this further.

Clear effects of indenter diameter on $E_{\text {eff }}$ were only apparent for small frogs where both 264 and $64 \mu \mathrm{m}$ diameter indenters were used (Fig. 6a, box plots for frogs 3 and 4). Here, statistically significant increases in $E_{\text {eff }}$ values were recorded using the smaller indenter. The most probable explanation of this is that small indenters measure stiffness over a smaller area and depth than larger ones. Thus, the $E_{\text {eff }}$ values estimated by the $64-\mu \mathrm{m}$ indenter were
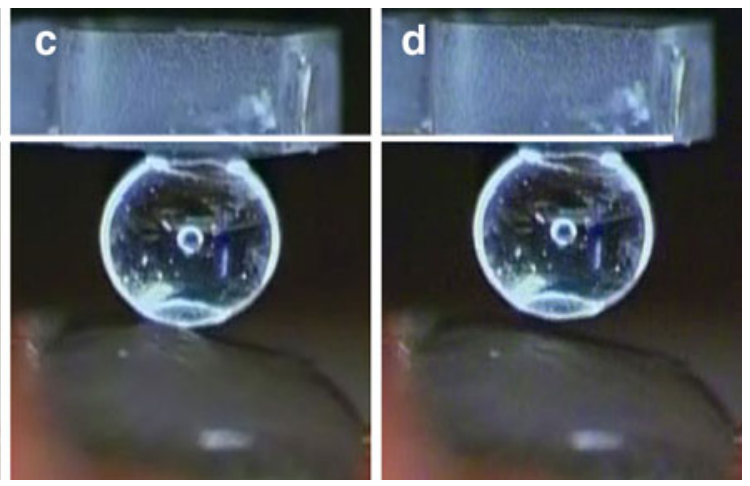

indenter, $\mathbf{d}$ end of indentation. These images come from the video (see Supplementary material)

less affected by the soft central parts of the toe pad. Comparisons of pad stiffness between juvenile and mature frogs can be obtained from the central four box plots of Fig. 5a. Here, the mature frogs had lower values for $E_{\text {eff }}$.

The work of adhesion or interfacial energy is the energy that must be expended to separate a unit area of interface, in our experiments the interface between the indenter and the toe pad. The usual units are $\mathrm{J} \mathrm{m}^{-2}$ (or their equivalent, $\mathrm{N} \mathrm{m}^{-1}$ ). The work of adhesion increased with indentation depth (Fig. 5b) for both frogs tested. It was also higher for the smaller than the larger frogs when they were compared (data from $264 \mu \mathrm{m}$-diameter indenter) (Fig. 6b). Effects of indenter diameter were less clear-cut, as values decreased when the indenter diameter was changed from 1.5 to $264 \mu \mathrm{m}$ (larger frogs), but increased when the indenter diameter was changed from 264 to $64 \mu \mathrm{m}$ (small frogs) (Fig. 6b).

The pull-off force is a direct measurement of pad adhesive force, but probably does not reflect the frog's adhesive abilities, since pads readily detach from surfaces when the pulling angle is $90^{\circ}$, but produce much greater adhesive forces at pulling angles of about $30^{\circ}$ (Barnes et al. 2008). The effects of indentation depth on pull-off force were ambiguous in the two frogs examined, since increasing depth lowered pull-off force in one frog, while increasing it in the other (Fig. 5c). More clear-cut results are seen when effects of frog size and indenter diameter were considered. Immature frogs had greater pull-off forces than adult ones (comparison with $264 \mu \mathrm{m}$-diameter indenter) (Fig. 6c), while reducing indenter diameter reduced pull-off forces in both adult and immature frogs (Fig. 6c).

\section{Discussion}

Physical properties of toe pads

The elastic modulus (or in our case, the effective elastic modulus as the Poisson's ratio for toe pads is not known) 

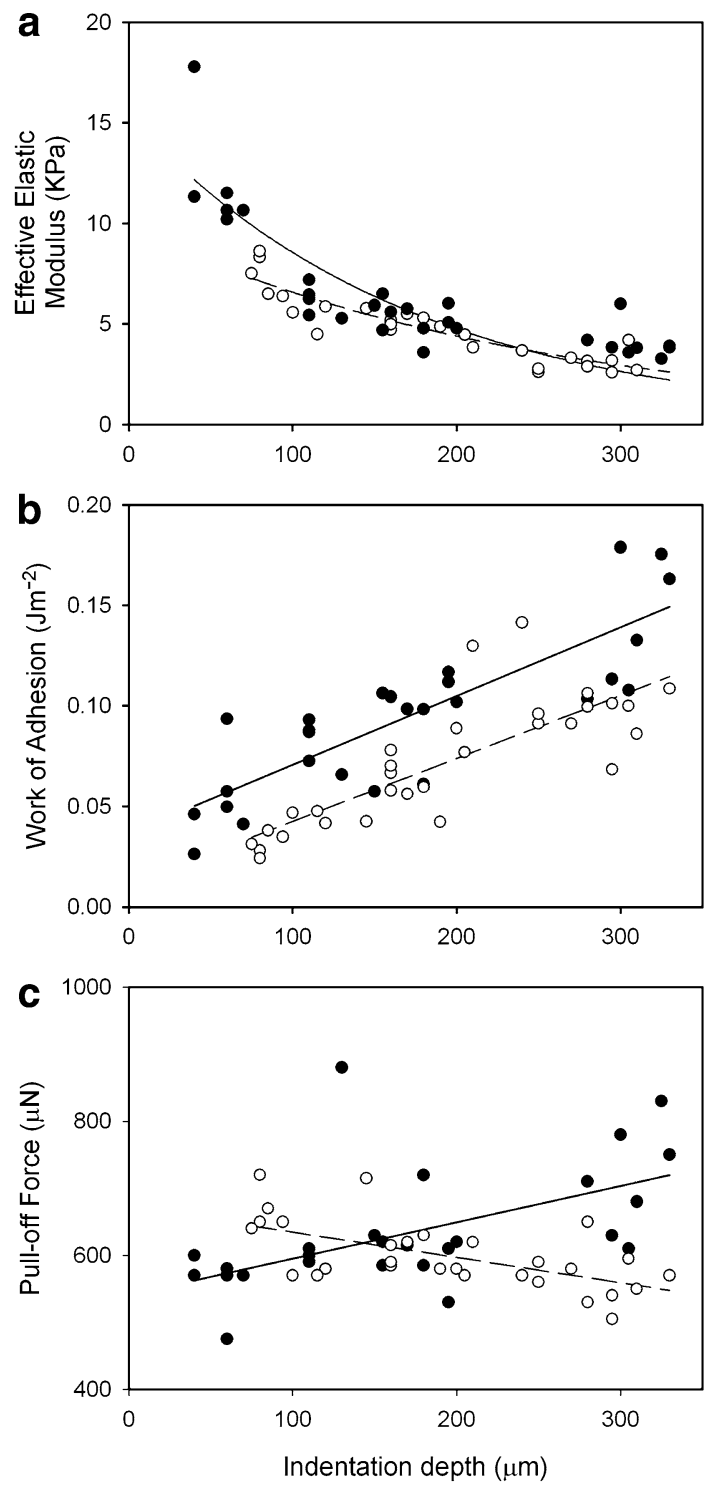

Fig. 5 Effects of indentation depth on effective elastic modulus (a), work of adhesion (b) and pull-off force (c). Open and filled circles represent data from the two mature adult frogs, frogs 1 and 2, respectively. The indenter used in these experiments was a $1.5-\mathrm{mm}$ sapphire sphere. The data in (a) were fitted by exponential curves of the form $y=y_{0}+a \mathrm{e}^{-b x}$, with statistical analyses using non-linear regression. Linear regression analysis was applied to the (b) and (c) data. Statistical significances $\left(r^{2}=\right.$ coefficient of determination; $b=$ slope of regression line; $p$ value, $t$ test): a filled circles, $r^{2}=0.73, p<0.001 ;$ open circles, $r^{2}=0.81, p<0.001$. b filled circles, $r^{2}=0.70, \quad b=3.42 \times 10^{-4}, \quad p<0.001 ;$ open circles, $r^{2}=0.65, b=3.13 \times 10^{-4}, p<0.001$. c filled circles, $r^{2}=0.31$, $b=0.54, p<0.01$; open circles, $r^{2}=0.37, b=-0.38, p<0.001$

provides a quantitative measure of material stiffness, an important parameter for adhesion. As Figs. 5a and 6a show, most of our measurements lie in the range 4-25 kPa. Toe pads are thus amongst the softest of biological
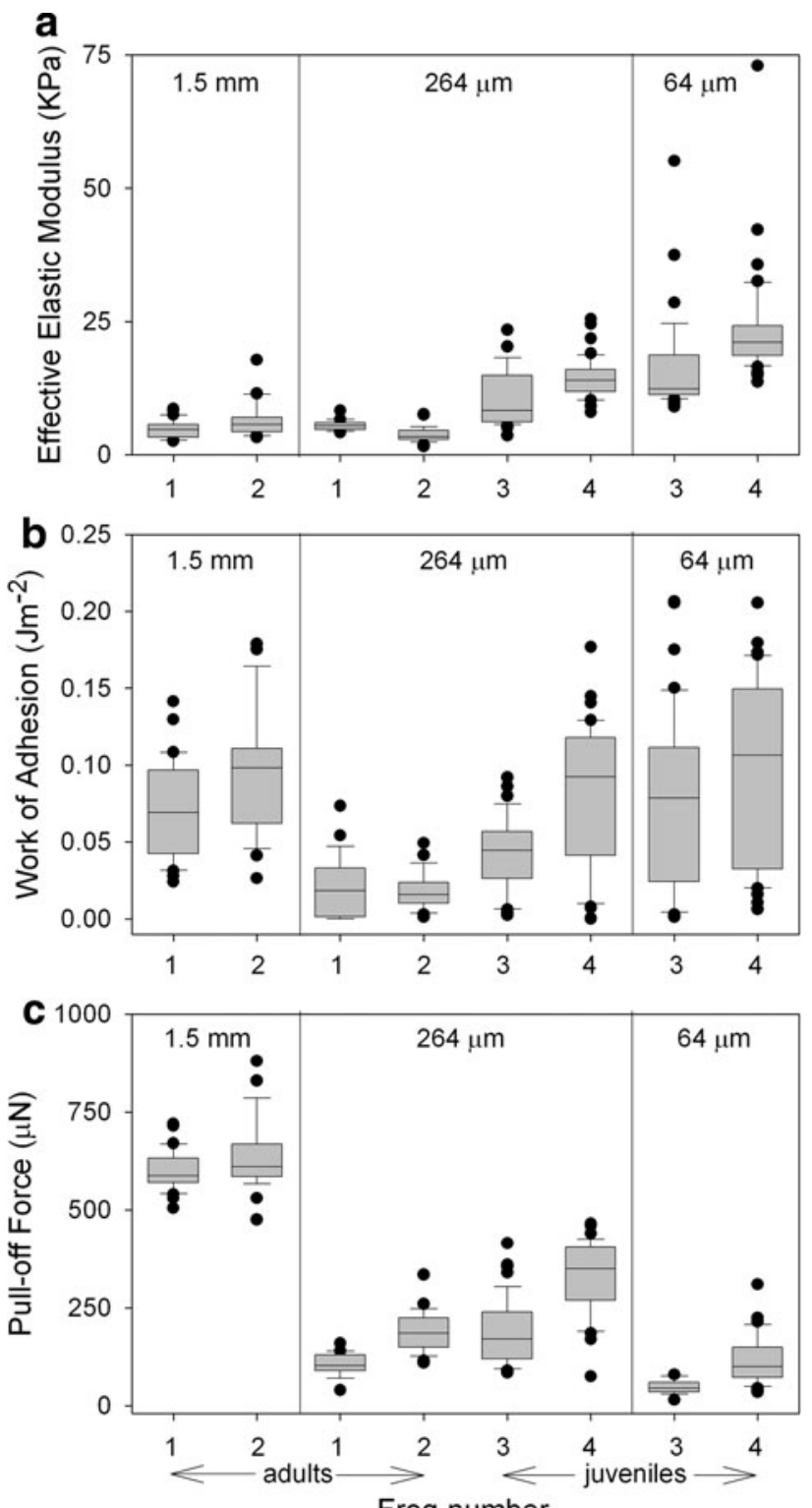

Frog number

Fig. 6 Effects of indenter diameter $(1.5 \mathrm{~mm}, 264$ and $64 \mu \mathrm{m})$ and frog age (frogs 1 and 2 were mature adults while frogs 3 and 4 were immature) on effective elastic modulus $\left(E_{\text {eff }}\right)(\mathbf{a})$, work of adhesion (b) and pull-off force (c). The box plots show median value (line), 25 and $75 \%$ percentiles (shaded area), 10 and $90 \%$ percentiles (error bars) and outliers (filled circles). Comparisons were made after combining data from similar sized frogs. The larger (adult) frogs had a lower $E_{\text {eff }}$, a lower work of adhesion and a lower pull-off force than the smaller (immature) frogs with the $264 \mu \mathrm{m}$-diameter indenter. For the large frogs, decreasing the indenter diameter from $1.5 \mathrm{~mm}$ to $264 \mu \mathrm{m}$ resulted in a small decrease in $E_{\text {eff }}$, a decrease in the work of adhesion and a large decrease in the pull-off force. For the small frogs, decreasing the indenter diameter from 264 to $64-\mu \mathrm{m}$ diameter resulted in an increase in $E_{\text {eff }}$, a small increase in the work of adhesion and a drop in the pull-off force. Because of the small sample size (two frogs of each age group), statistical tests cannot be used to test the significance of these differences 
materials, equivalent to jellyfish jelly or sea anemone mesogloea $(E \approx 10 \mathrm{kPa})$. Although not as soft as adipose tissue ( $E \approx 3 \mathrm{kPa}$; Samani et al. 2007), values are much lower than for aorta $(E \approx 500 \mathrm{kPa})$, cartilage $(E \approx$ $20 \mathrm{MPa})$ or for that matter silicone rubber $(E \approx 1 \mathrm{MPa})$. At the opposite extreme, tooth enamel has an $E$ value of $60,000 \mathrm{MPa}$. Tables showing Young's moduli of elasticity for common biological materials appear in Vogel (2003), from which the above examples were taken. Elastic moduli of smooth adhesive pads of ensiferan insects (crickets, long-horned grasshoppers) are comparable with those obtained for tree frogs $(25-100 \mathrm{kPa})$, whereas the moduli of caeliferan insects (locusts, short-horn grasshoppers) are much higher (250-750 kPa) (Perez Goodwyn et al. 2006).

Tree frog toe pads do not, however, have a uniform stiffness. As Scholz et al. (2009) showed, the epithelial surface has a much higher stiffness $(5-15 \mathrm{MPa})$ as measured by atomic force microscopy, while this study (Fig. 5a) showed an inverse relationship between indentation depth and stiffness, implying the presence of softer materials beneath the surface. Such a gradient of stiffness fits well with toe pad histology, since the outer cell layer is keratinised and a capillary network lies beneath the epidermis (Fig. 2). Such an arrangement might provide an abrasion-resistant outer layer that, due to the soft tissues and fluids lying beneath, would have enough flexibility to allow a degree of moulding to surface asperities, thus enhancing both friction and adhesion. Similar gradient properties were obtained for smooth adhesive pads of orthopteran insects Tettigonia viridissima and Locusta migratoria (Gorb et al. 2000; Perez Goodwyn et al. 2006). It seems that such an optimised solution for (1) increased ability to form an intimate contact with various surface profiles and (2) increased wear resistance evolved independently in smooth attachment devices of such distantly related animal groups as insects and frogs.

These conclusions do, however, contrast with AFM data recently obtained on the smooth adhesive pads of stick insects (Scholz et al. 2008). These authors showed that an extremely soft outer layer, presumed to be the epicuticle, overlies a much stiffer one (the procuticle). Such an arrangement will promote good conformation to surface asperities, but at the expense of wear resistance. Although these results contradict previous data on the epicuticle of other insects (Barbakadze et al. 2006), it is important to point out that stiffness differences between adhesive pad cuticle and cuticle from elsewhere in the body might be expected. Also, the indentation depths $(>35 \mu \mathrm{m})$ used by Gorb et al. (2000) and Perez Goodwyn et al. (2006) would not have resolved the stiffness of a layer as thin as the epicuticle (thickness 100-300 nm).

Although our sample size is small, our study also suggests that the toe pads of the mature frogs have significantly lower values for $E_{\text {eff }}$ than immature ones, a fact that could at least partly explain the increased toe pad efficiency of $L$. caerulea with age (Wuttke et al. 2008). Surprisingly, the material itself in older individuals (as we show in this study) has a lower work of adhesion and generated lower pull-off forces than that in younger individuals. We can only explain this contradictory effect by the fact that the pads of adult frogs are larger and less domed (larger radii of curvature) than those of smaller frogs (Table 1). The stiffer outer surface of toe pads (Scholz et al. 2009) would be more resistant to indentation when it was more domed. This effect may give rise to increased values of $E_{\text {eff }}$ in immature frogs.

The work of adhesion increased with indentation depth (Fig. 5b) for both frogs tested. A possible explanation is that viscoelastic properties of the pad may cause such an adhesion-on-depth effect. The resting part of the force-time curve (Fig. 1b) shows that the pad material relaxes under the applied load. At higher indentation depth, due to the material relaxation, the real contact area between both the indenter and pad will be higher than that predicted by JKR (which assumes ideally elastic materials in contact). Because of such a disproportionally increased contact area, the work of adhesion will be stronger at higher indentation depths (according to JKR, it should not change). It was also higher for the younger than for the older frogs when they were compared (data from $264 \mu \mathrm{m}$-diameter indenter) (Fig. 6b). Immature frogs also had greater pull-off forces than adult ones (comparison with $264 \mu \mathrm{m}$-diameter indenter) (Fig. 6c). Certainly, biological materials change with age. It has been previously shown that younger cockroaches have softer adhesive pads and perform better on smooth inclines than older ones (Ridgel et al. 2003; Ridgel and Ritzmann 2005).

In both adult and immature frogs, higher pull-off forces were obtained with larger indenters. This is not surprising, because of the greater area of contact, as theory would predict (Butt et al. 2010).

Possible role of blood system in toe pad function

It is well established that some insect smooth pads, for example the arolia of bees and ants, can be inflated hydraulically by increases in haemolymph pressure (Federle et al. 2001). However, to the best of our knowledge, our finding that there is a dense network of capillaries in the dermis beneath the toe pads of L. caerulea has not been previously noted. It is, however, strikingly similar to the blood sinuses that occur beneath the hairy adhesive pads of geckos (Russell 1975). These structures are thought to act as a hydrostatic skeleton maintaining pressure on the scansors that hold the adhesive setae. Flexion of the digit causes the penultimate phalanx to press down on the sinus, bringing about an increased pressure that causes the pad to 
be pressed onto the substrate. Promoting close contact with the substrate when increased adhesion or friction was required could also be a role for the capillary network in $L$. caerulea. However, a more important role of the sinus is likely to act as a shock absorber. This is particularly important when landing on a vertical surface after a jump. Having soft inelastic material beneath the pad reduces the risk of elastic recoil, increases contact time for adhesion and increases contact area. The soft pad will also mould itself to the contours of the landing surface. Since blood pressure is under physiological control, there is also the possibility of the frog altering the stiffness of its pads according to need. The limbs, especially the forelimbs, also play an important role during landing after a jump in damping the kinetic energy of the flight phase (Nauwelaerts and Aerts 2006).

\section{Biomimetic relevance}

Most man-made adhesive tapes are poor at adhering to the wet and flooded surfaces that tree and torrent frogs are able to climb on and, therefore, unravelling and understanding the frog's solution is of significant scientific and technological relevance. Such a study must necessarily involve both observation and studies of the biological system, and fabrication of simplified artificial toe pad models where the effect of the individual design parameters can be analysed and quantified precisely. Such a combination of methods will allow us to establish the design principles necessary to obtain artificial analogues with similar performance. This paper, for instance, has demonstrated the need for such analogues to be made out of soft materials having particular mechanic properties.

Up until now, attempts to enhance adhesion in wet conditions based on natural principles have mainly concentrated on the gluing mechanisms of mussels (Lee et al. 2006, 2007), though one of us has been studying the properties of micropatterned surfaces inspired by insect adhesive mechanisms (Varenberg and Gorb 2008, 2009). Like these micropatterned insect-inspired surfaces, tree frog pad-inspired adhesives seem to rely on a particular surface topographic design and less on the presence of particular chemical compounds. This seems to be a more generic principle, able to be implemented in a great variety of technological sectors. Improved wet weather tyres (Barnes 1999; Barnes et al. 2002; Persson 2007), non-slip footwear, plasters for surgery able to adhere to tissue and holding devices for neurosurgery or MEMS devices are examples of the many uses to which these toe pad analogues might be applied.

Acknowledgments The authors thank Andrei Peressadko for providing the software "Fitting Tools" for data processing. This work, part of the European Science Foundation EUROCORES Programme FANAS, was supported from funds by the German Science Foundation DFG (Contract No. GO 995/4-1) and the EC Sixth Framework
Programme (Contract No. ERAS-CT-2003-980409) to SG and grants from the Wellcome Trust (Showcase Award; Grant No. 070924) and the German Science Foundation DFG (Priority Programme SPP 1420, Reference No. BA 3989/1-1) to WJPB. All experimental procedures described above were carried out in accordance with current laws on animal experimentation in Germany.

Open Access This article is distributed under the terms of the Creative Commons Attribution Noncommercial License which permits any noncommercial use, distribution, and reproduction in any medium, provided the original author(s) and source are credited.

\section{References}

Autumn K, Sitti M, Liang YCA, Peattie AM, Hansen WR, Sponberg S, Kenny TW, Fearing R, Israelachvili JN, Full RJ (2002) Evidence for van der Waals adhesion in gecko setae. Proc Natl Acad Sci USA 99:12252-12256

Barbakadze N, Enders S, Gorb SN, Arzt E (2006) Local mechanical properties of the head articulation cuticle in the beetle Pachnoda marginata (Coleoptera, Scarabaeidae). J Exp Biol 209:722-730

Barnes WJP (1999) Tree frogs and tire technology. Tire Technol Int, pp 42-47

Barnes WJP (2007) Functional morphology and design constraints of smooth adhesive pads. Mater Res Soc Bull 32:479-485

Barnes WJP, Smith J, Oines C, Mundl R (2002) Bionics and wet grip. Tire Technol Int, pp 56-60

Barnes WJP, Perez-Goodwyn P, Gorb SN (2005) Mechanical properties of the toe pads of the tree frog, Litoria caerulea. Comp Biochem Physiol A 141:145

Barnes WJP, Pearman J, Platter J (2008) Application of peeling theory to tree frog adhesion, a biological system with biomimetic implications. Eur Acad Sci E-Newslett Sci Technol 1(1):1-2

Berger VY, Naumov AD (1996) Influence of salinity on the ability of starfishes Asterias rubens L. to attach to substrate. Biologiya Morya 22:99-101

Butt H-J, Barnes WJP, Del Campo A, Kappl M (2010) Capillary forces between soft, elastic spheres. Soft Matter 6:5930-5936

Duellman W, Trueb L (1997) Biology of amphibians, 2nd edn. Johns Hopkins University Press, Baltimore

Emerson SB, Diehl D (1980) Toe pad morphology and mechanisms of sticking in frogs. Biol J Linn Soc 13:199-216

Ernst V (1973) The digital pads of the tree frog, Hyla cinerea: 1 . The epidermis. Tissue Cell 5:83-96

Feder HM (1955) On the method used by the starfish Pisaster ochraceus in opening three types of bivalve molluscs. Ecology 36:764-767

Federle W, Brainerd EL, McMahon TA, Hőlldobler B (2001) Biomechanics of the movable pretarsal adhesive organ in ants and bees. Proc Natl Acad Sci USA 98:6215-6220

Federle W, Barnes WJP, Baumgartner W, Dreschler P, Smith JM (2006) Wet but not slippery-boundary friction in tree frog adhesive toe pads. J R Soc Interface 3:589-601

Flammang P (1996) Adhesion in echinoderms. Echinoderm Studies 5:1-60

Flammang P, Walker G (1997) Measurement of the adhesion of the podia in the asteroid Asterias rubens (Echinodermata). J Mar Biol Assoc UK 77:1251-1254

Flammang P, Demeulenaere S, Jangoux M (1994) The role of podial secretions in adhesion in two species of sea stars (Echinodermata). Biol Bull 187:35-47

Flammang P, Michel A, van Cauwenberge A, Alexandre H, Jangoux M (1998) A study of the temporary adhesion of the podia in the sea 
star Asterias rubens (Echinodermata, Asteroidea) through their footprints. J Exp Biol 201:2383-2395

Gorb SN, Jiao Y, Scherge M (2000) Ultrastructural and mechanical properties of attachment pads in Tettigonia viridissima (Orthoptera, Tettigonidae). J Comp Physiol A 186:821-831

Green DM (1979) Treefrog toe pads: comparative surface morphology using scanning electron microscopy. Can J Zool 57:2033-2046

Green DM, Alberch P (1981) Interdigital webbing and skin morphology in the neotropical salamander genus Bolitoglossa. J Morphol 170:273-282

Hanna G, Barnes WJP (1991) Adhesion and detachment of the toe pads of tree frogs. J Exp Biol 155:103-125

Hertz H (1881) Über den Kontakt elastischer Körper. Reine Angew Math 92:156-171

Hiller U (1968) Untersuchungen zum Feinbau und zur Funktion der Haftborsten von Reptilien. Z Morphol Tiere 62:307-362

Huber G, Mantz H, Spolenak R, Mecke K, Jacobs K, Gorb SN, Arzt E (2005a) Evidence for capillarity contributions to gecko adhesion from single spatula nanomechanical measurements. Proc Natl Acad Sci USA 102:16293-16296

Huber G, Gorb SN, Spolenak R, Arzt E (2005b) Resolving the nanoscale adhesion of individual gecko spatulae by atomic force microscopy. Biol Lett 1:2-4

Imai Y, Sue A, Yamaguchi A (1968) A removing method of the resin from epoxy-embedded sections for light microscopy. J Electron Microsc 17:84-85

Johnson KL (1985) Contact mechanics. Cambridge University Press, Cambridge

Johnson KL, Kendall K, Roberts AD (1971) Surface energy and the contact of elastic solids. Proc R Soc Lond A 324:301-313

Kendall K (2001) Molecular adhesion and its applications. Klewer, New York

Kohane M, Daugela A, Kutomi H, Charlson L, Wyrobek A, Wyrobek J (2003) Nanoscale in vivo evaluation of the stiffness of Drosophila melanogaster integument during development. J Biomed Mater Res A 66:633-642

Lavoie ME (1956) How sea stars open bivalves. Biol Bull 111:114-122

Lee H, Scherer NF, Messersmith PB (2006) Single molecule mechanics of mussel adhesion. Proc Natl Acad Sci USA 103:12999-13003

Lee H, Lee BP, Messersmith PB (2007) A reversible wet/dry adhesive inspired by mussels and geckos. Nature 448:338-341

Nauwelaerts S, Aerts P (2006) Take-off and landing forces in jumping frogs. J Exp Biol 209:66-77

Paine VL (1926) Adhesion of the tube feet in starfishes. J Exp Zool 45:361-366

Peressadko AG, Hosoda N, Persson BNJ (2005) Influence of surface roughness on adhesion between elastic bodies. Phys Rev Lett 95:124301

Perez Goodwyn P, Peressadko A, Schwarz H, Kastne V, Gorb S (2006) Material structure, stiffness, and adhesion: why attachment pads of the grasshopper (Tettigonia viridissima) adhere more strongly than those of the locust (Locusta migratoria) (Insecta: Orthoptera). J Comp Physiol A 192:1233-1243

Persson BNJ (2007) Wet adhesion with application to tree frog adhesive toe pads and tires. J Phys Cond Matter 19:376110 (16 pp)

Persson BNP, Gorb SN (2003) The effect of surface roughness on the adhesion of elastic plates with application to biological systems. J Chem Phys 119:11437-11444

Persson BNP, Albohr O, Tartaglino U, Volokitin AI, Tosatti E (2005) On the nature of surface roughness with application to contact mechanics, sealing, rubber friction and adhesion. J Phys Condens Matter 17:R1-R62

Ridgel AL, Ritzmann RE (2005) Insights into age-related locomotor declines from studies of insects. Ageing Res Rev 4:23-39
Ridgel AL, Ritzmann RE, Schaefer PL (2003) Effects of aging on behavior and leg kinematics during locomotion in two species of cockroach. J Exp Biol 206:4453-4465

Riskin DK, Fenton MB (2001) Sticking ability in Spix’s disk-winged bat, Thyroptera tricolor (Microchiroptera, Mammalia). Can J Zool 79:2261-2267

Russell AP (1975) A contribution to the functional analysis of the foot of the Tokay, Gecko gecko (Reptilia: Gekkonidae). J Zool Lond 176:437-476

Samani A, Zubovitz J, Plewer D (2007) Elastic moduli of normal and pathological human breast tissue: an inversion-technique-based investigation of 169 samples. Phys Med Biol 52:1565-1576

Santos R, Flammang P (2005) Morphometry and mechanical design of tube foot stems in sea urchins: a comparative study. J Exp Mar Biol Ecol 315:211-223

Santos R, Gorb S, Jamer V, Flammang P (2005a) Adhesion of echinoderm tube feet to rough surfaces. J Exp Biol 208:2555-2567

Santos R, Haesaerts D, Jangoux M, Flammang P (2005b) Comparative histological and immunohistochemical study of sea star tube feet (Echinodermata, Asteroidea). J Morphol 263:259-269

Scherge M, Gorb S (2001) Biological micro- and nano-tribology: nature's solutions. Springer, Heidelberg

Schliemann H (1970) Bau und function der Haftorgane von Thyroptera und Myzopoda (Vespertilionoidea, Microchiroptera, Mammalia). Z Wiss Zool 181:353-400

Schliemann H (1971) Die Haftorgane von Thyroptera und Myzopoda (Microchiroptera, Mammalia)—Gedanken zu ihrer Entstehung als Parallelbildungen. Z Zool Syst Evolutionsforsch 9:61-80

Schliemann H (1974) Haftorgane bei Fledermäusen. Natur und Museum 104:15-20

Schliemann H (1975) Über die Entstehung von Haftorganen bei Chiropteren. Mitt Hamb Zool Mus Inst 72:249-259

Schliemann H (1983) Haftorgane-Beispiele für gleichsinnige Anpassungen in der Evolution der Tiere. Funkt Biol Med 2:169-177

Schliemann H, Hoeber M (1978) Über die Bambusfledermaus. Natur und Museum 108:44-48

Schliemann H, Rehn C (1980) Zur Kenntnis der Haftorgane von Eudiscopus denticulus (Osgood, 1932) (Mammalia, Microchiroptera, Vespertilionidae). Z Säugetierkunde 45:29-39

Scholz I, Baumgartner W, Federle W (2008) Micromechanics of smooth adhesive organs in stick insects: pads are mechanically anisotropic and softer towards the adhesive surface. J Comp Physiol A 194:373-384

Scholz I, Barnes WJP, Smith JM, Baumgartner W (2009) Ultrastructure and physical properties of an adhesive surface, the toe pad epithelium of the tree frog, Litoria caerulea White. J Exp Biol 212:155-162

Smith JM, Barnes WJP, Downie JR, Ruxton GD (2006) Structural correlates of increased adhesive efficiency with adult size in the toe pads of hylid tree frogs. J Comp Physiol A 192:1193-1204

Thewissen JGM, Etnier SA (1995) Adhesive devices on the thumb of vespertilionoid bats (Chiroptera). J Mammalogy 76:925-936

Thomas LA, Hermans CO (1985) Adhesive interactions between the tube feet of a starfish, Leptasterias hexactis, and substrata. Biol Bull 169:675-688

Varenberg M, Gorb SN (2008) A beetle-inspired solution for underwater adhesion. J R Soc Interface 5:383-385

Varenberg M, Gorb SN (2009) Hexagonal surface micropattern for dry and wet friction. Adv Mater 21:483-486

Varenberg M, Pugno NM, Gorb SN (2010) Spatulate structures in biological fibrillar adhesion. Soft Matter 6:3269-3272

Vogel S (2003) Comparative biomechanics: life's physical world. Princeton University Press, Oxford

Wuttke St, Matz D, Barnes WJP (2008) Sticky solutions: how the tree frog Litoria caerulea solves the allometry problem. Comp Biochem Physiol A 150:S90 